\title{
CONTEXTO HISTÓRICO DA FORMAÇÃ̃O DO TALIAN: ALGUMAS CONSIDERAÇÕES
}

\author{
Alessandra Regina Ribeiro* \& Giliola Maggio **
}

RESUMO: O objetivo deste artigo é apresentar reflexões sobre o contexto histórico da formação do Talian. A língua constituiu-se no Brasil a partir do contato com os dialetos de origem italiana - que chegaram com a Primeira Grande Imigração - somados a empréstimos da língua portuguesa brasileira local, isto é, dos municípios da Região de Colonização Italiana do Rio Grande do Sul, Santa Catarina, Paraná e Espírito Santo. No presente estudo, sinalizamos para as possibilidades que constituíram o nome dessa língua. Além disso, destacamos a importância de se compreender as interinfluências das línguas em contato e como compreendemos que tais influências seriam naturais. Para finalizar, trazemos alguns autores e eventos midiáticos que trabalham em prol da divulgação desse idioma.

PALAVRAS-CHAVE: talian; imigração Italiana; mescla; Brasil.

ABSTRACT: L'obiettivo del presente articolo è presentare riflessioni sul contesto storico della formazione del Talian. La lingua si è costituita in Brasile a partire dal contatto con i dialetti di origine italiana, giunti con la prima grande ondata di immigrazione, sommati ai prestiti della lingua portoghese brasiliana locale, di città della zona di colonizzazione italiana negli stati di Rio Grande do Sul, Santa Catarina, Paraná e Espírito Santo. In questo studio, passiamo in rassegna le possibilità che hanno portato alla costituzione del nome di questa lingua. Inoltre, evidenziamo l'importanza di capire le interinfluenze tra le lingue in contatto e come intendiamo che queste influenze sono naturali. Per concludere, presentiamo alcuni degli autori e degli eventi mediatici che contribuiscono alla promozione di questa lingua.

PAROLE-CHIAVE: talian; immigrazione Italiana; mescolanza linguistica; Brasile.

ABSTRACT: The aim of this article is to present some reflexions about the historical background of the formation of the language called Talian - constituted in Brazil from the encounter of italian dialects of the First Great Immigration, and loanwords of

\footnotetext{
* Universidade do Oeste do Paraná (UNIOESTE) - profalessandra.ribeiro@gmail.com

** Universidade de São Paulo (USP) - gilimaggio@gmail.com

DOI: http://dx.doi.org/10.11606/issn.2238-8281.v0i38p73-87
} 
the local Portuguese-Brazilian language. This is, in particular, the language of cities from a Region of Italian Colonization in the Brazilian states of Rio Grande do Sul, Santa Catarina, Paraná and Espírito Santo. In this study, we indicate hypotheses about the reasons why this language may have been called Talian. Furthermore, we highlight the importance of understanding the inter-influences of languages which are in contact and how we understand such influences as natural. To conclude we cite authors and media events that work for the promotion of the Talian language.

KEYWORDS: talian; italian immigration; language miscellaneous; Brazil. 


\section{Introdução}

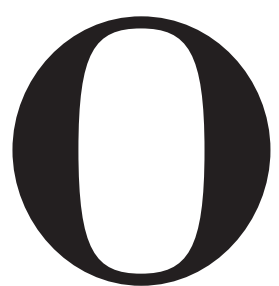

presente artigo tem como objetivo apresentar algumas das pesquisas que se dedicaram à constituição do talian, uma língua que se formou no Sul do Brasil, no final do século XIX, com a chegada de imigrantes e descendentes de italianos, vindos de uma Itália há pouco unificada geograficamente, mas ainda não linguisticamente. É por isso que a chamada "Primeira Grande Imigração" levou para o contexto do Sul brasileiro diversos falares dialetais das regiões italianas, de modo que o talian é o resultado da mistura dos dialetos vêneto, lombardo e trentino, somados a empréstimos lexicais e também morfossintáticos do português brasileiro regional.

Serão sinalizadas também algumas das possibilidades do que se considera ter levado a denominar essa língua talian. Em seguida, serão pontuados eventos, personagens e publicações que contribuem para sua difusão e manutenção.

\section{Descendentes de italianos em busca de uma língua}

O talian é caracterizado como língua de minoria. Como já dissemos, formou-se no Brasil, à época da primeira leva de imigração, quando imigrantes e descendentes de italianos se fixaram nos estados do Rio Grande do Sul e de Santa Catarina. Nos estudos consultados, encontramos, também, a denominação vêneto brasileiro ou dialeto sul rio-grandense (FROSI \& RASO, 2011).

O nome ligado ao Vêneto se explica pela predominância de dialetos dessa região, já que a constituição do talian vai acontecendo à medida que tais dialetos vão se intercruzando. Além disso, com a necessidade de comunicação com brasileiros, vão sendo igualmente incorporadas palavras e estruturas da língua portuguesa (LUZZATTO, 1993; CONFORTIN, 1998).

O talian teve grande difusão, tanto que Luzzatto (1993) chega a afirmar que seria a segunda língua mais falada no Brasil, posicionando-se depois do português. Desconhecemos pesquisas que demonstrem tal dado, mas uma indicação que confirmaria a hipótese está no fato de que no Rio Grande do Sul, em municípios como Caxias do Sul, Bento Gonçalves, Garibaldi, Serafina Corrêa, Antônio Prado, Erechim, entre outros, o talian é a língua materna de muitos anciãos, 
principalmente, daqueles que residem na zona rural.

Vale frisar que não é somente a "língua do imigrante" que é veiculada, mas também sua cultura, que se reflete na alimentação, na religiosidade e nas festas. Assim, cidades como Caxias do Sul, Bento Gonçalves, Serafina Corrêa, entre outras, preconizam manifestações culturais locais que têm o talian como língua co-oficial.

Um dado que é importante destacar para um melhor entendimento da situação é que os imigrantes foram estabelecidos em glebas de terras próximas umas das outras, ficando isolados geográfica e socialmente da zona urbana. Isso contribuiu para uma maior aproximação entre eles e para a convivência em comunidade, de modo que as pessoas, aos poucos, foram se comunicando em suas línguas e se "interinfluenciando".

Em virtude do seu processo de unificação, que aconteceu entre 1859 e 1870, a Itália acabou tomando rumos capitalistas, o que gerou um grande contingente de pessoas sem terra e sem trabalho. De acordo com Carboni e Maestri (2000, p. 16), “O abandono da terra natal constituiu saída para a crise vivida por multidões de camponeses [...]”, de maneira que os campesinos perderam seus postos, dando lugar à propriedade privada e à industrialização. Com representatividade numérica, italianos migraram especialmente da região do Vêneto, da Lombardia, do Trentino Alto Ádige (Tirol) e do Friuli Venezia Giulia (FROSI \& MIORANZA, 1975, p. 15). Sem terras, sem trabalho, sem condições mínimas de sobrevivência, eles deixaram a Itália para fugir dos pesados impostos ou, ainda, após perderem suas terras para o fisco, para os agiotas, para os burgueses citadinos, para os grandes proprietários. Devido à impraticabilidade do contexto em que viviam, esses italianos iniciaram, por causa das migrações, novas histórias de vida e, por conseguinte, novas histórias linguísticas.

Há um outro aspecto que deve ser levado em conta: os imigrantes não falavam a língua italiana, mas vários dialetos e transferiram para o Brasil a situação linguística daquele momento. No Norte da Itália, por exemplo, que era governado direta ou indiretamente por estrangeiros, não havia unidade política e linguística, de modo que, de acordo com o que afirma Luzzatto (1998, p. 168), quase todos os componentes das primeiras levas de imigrantes não eram "italianos", mas vênetos, lombardos, friulanos, trentinos, piemonteses etc. e trouxeram da Itália seus falares. Da região do Vêneto, vieram, por exemplo, os seguintes dialetos: belunês, trevisano, vicentino, veronês, veneziano; da região da Lombardia: mantuano, cremonês, milanês; da região do Friuli: um vêneto arcaico; da região de Trento: variante do vêneto e o trentino, que por sua vez, era composto por outros e importantes contatos, como o austríaco (LEOPOLDINO, 2014). Luzzatto (1993), ao discorrer sobre a história do Talian, registra ainda que:

Nossos antepassados, quando chegaram da Itália, utilizavam falares diferentes, característicos de sua região de origem. Aqui, o governo imperial, que não distinguia um trentino de um friulano, assentou-os todos juntos. Dessa mescla de gentes, e, consequentemente de falares, resultou um novo idioma, o talian. (p. 30) 
Essa descrição evidencia que a língua materna do imigrante era a língua do seu paese, isto é, do pequeno povoado do qual era originário, que, em contato com outros falares dialetais, foi se modificando, formando uma língua comum a todos. As "línguas de partida" e as "línguas de chegada", como diria Weinreich (2008), levaram assim à constituição de algo novo, resultado do contato entre elas.

\section{A definição do nome talian}

No que concerne à definição do nome talian, existem algumas considerações de autores gaúchos que nos permitem evidenciar que a escolha tem a ver com a difícil história das vidas dos imigrantes, embora, no Brasil, esse nome revele muito sobre o lugar de origem. Sua construção, portanto, vai sendo moldada na relação afetiva de seus falantes. É o que podemos notar, a seguir, nas justificativas de alguns autores.

Honorio Tonial $^{1}(2008$, n.p.) aponta que, da confluência dos diferentes falares trivênetos e lombardos e, em número menor, dos falares de outras regiões, acrescidos de palavras da língua portuguesa, formou-se uma nova língua denominada pelos estudiosos talian, pois, ao que tudo indica e como veremos nos próximos parágrafos, o termo já existia na Itália. $\mathrm{O}$ autor relata que esse nome foi escolhido justamente porque permitia que fosse diferenciado da língua italiana oficial. Por isso, os descendentes pertencentes ao trivêneto-lombardo (1875-1945), que vieram ao Brasil em busca de uma vida melhor, foram denominados taliani no Brasil. Sabemos, no entanto, que muitos desses descendentes que falam "essa mistura de dialetos com português" não têm uma definição da língua que veiculam, tanto que é comum lermos e ouvirmos relatos em que afirmam falar o dialeto ou o italiano "não gramatical".

Luzzatto (1993), ao expor suas conjecturas a respeito de sua própria língua, conta que, em conversas com alguns estudiosos, pediam-lhe esclarecimentos sobre seu falar, pois uns o caracterizavam como um "falar vêneto", outros como "vêneto brasileiro", "falar vêneto com sotaque trentino" e outros ainda, como "talian" (p. 22). Todas as descrições levavam-no a acreditar que sua língua era, de fato, tudo aquilo, já que se tratava de uma mistura das línguas em contato. Conforme descreve o próprio autor, o talian era uma verdadeira língua vernácula nos anos 50, momento de grande incidência da migração para Santa Catarina e regiões Sudoeste e Oeste do Paraná. Naquela ocasião, ainda não se tinha estabelecido um nome para a língua e, assim, denominavam-na simplesmente de dialeto vêneto ou de vêneto, embora, segundo o autor, "não fosse um vêneto perfeito" (sic) (LUZZATTO, 1993, p. 23), visto que havia a contribuição de outros dialetos do Norte e do Nordeste da Itália e, cada vez mais, palavras brasileiras venetizadas.

Retomando a questão quanto ao nome da língua que se formou no Brasil, durante esse longo período, em 1987, em Porto Alegre, com a presença de alguns pesquisadores que falavam e

1 Disponível em:<http://htonial.blogspot.com.br/search?updated-min=2008-01-01 T00:00:0008:00\&updated-max=2009-01-01T00:00:00-08:00\&max-results=34>. Acesso em: 03 set. 2019. 
escreviam nesse então considerado "dialeto", aconteceram reuniões para o estabelecimento de uma ortografia básica. Vale realçar que o desejo de reconhecimento do talian passa pelo viés da língua legitimada, que precisa ser oficializada pelas normas da escrita para ser aceita como língua.

Luzzatto (1993) faz, assim, uma descrição do momento em que se definiu a opção pela denominação da língua. Estavam presentes Darcy Luzzatto, Rovílio Costa, Júlio Posenato e outros estudiosos. Além da ortografia, eles estavam empenhados em designar uma atribuição única e definitiva para o falar vêneto, isto é, um nome que fosse mais conhecido pelos falantes. Rovílio Costa desejava que fosse "Vêneto Sul-riograndense", Luzzatto considerava que seria melhor "Vêneto Brasileiro" e Posenato preferia "Talian". Marcaram um encontro para outra data. Em uma ida de Luzzatto à cidade de Farroupilha, no Rio Grande do Sul, para a participação em um seminário, enquanto esperava uns amigos, na porta do local, ele viu uma idosa que aguardava o final da reunião. O autor aproximou-se e perguntou:

Scolté, nona, sio bona de capirme se ve parlo in vèneto? (Escute, Vó, a $\mathrm{Sr}^{\mathrm{a}}$. consegue entende-me se lhe falo em veneto?) E ela olhou-me fixamente $e$ depois me respondeu: Nò, caro, scùseme, sol se te me parli in talian! (Não, querido, só se me falares em talian!) (sic). (LUZZATTO, 1993, p. 23)

Depois disso, Luzzato e Posenato conversaram e concordaram que o nome da língua deveria ser, de fato, talian. Em nosso entendimento, não se sabe, ao certo, como o nome da língua foi se constituindo, mas nossa hipótese, baseada nessas citações, é a de que foi uma denominação muito mais ligada ao italiano. Inferimos ainda que, primeiro, apesar de não haver uma língua unificada, já havia o conceito abstrato de "italiano"; ou seja, todos vieram de um país que, embora não unificado do ponto de vista linguístico, politicamente já era conhecido como Itália. Ao buscarmos o significado de italiano no dicionário online Treccani, vimos que está caracterizado como:

Da Itália: o povo italiano; língua, história e literatura italiana; a civilização, a cultura, as costas, as regiões, as cidades, as províncias; a República Italiana, seja aquela proclamada por Napoleão em 1802 (como transformação da República Cisalpina), seja aquela nascida a partir do referendum de 02 de junho de $1946 .^{2}$ ( grifo nosso)

Entendemos, portanto, que, desde momentos políticos mais remotos, antes mesmo que "emigrasse", o conceito de italiano já existia; ou seja, partindo da definição do dicionário, é italiano tudo aquilo que está na península itálica como civilização, cultura, províncias e cidades.

Outra suposição seria que os militantes fervorosos, observando a frequência da utilização do termo talian, concluíram que seria o mais próximo a seus falantes. Entretanto, não foram encontradas outras referências bibliográficas brasileiras que possam confirmar a justificativa da escolha de tal nome. Para Costa, há relação com laços informais ligados à língua oral dos noni;

2 Dell'Italia: il popolo italiano; lingua, storia, letteratura italiana; la civiltà, la cultura; le coste, le regioni, le città, le province; la Repubblica Italiana, sia quella proclamata da Napoleone nel 1802 (come trasformazione della Repubblica Cisalpina) sia quella nata dal referendum del 2 giugno 1946. (Tradução nossa. Todas as traduções realizadas ao longo desta pesquisa são de autoria do próprio pesquisador.) 
logo, segundo o autor: "O nome talian veio dos nonos, que sempre diziam: Nós somos Taliani e por isso falamos em Talian".3(2000, p. 20)

Mas qual seria a razão da frequência do uso de tal nome? Aventamos a possibilidade de essas pessoas 'acreditarem' que a língua que estavam falando com seus compaesani, isto é, com pessoas nascidas ou que moravam em sua cidade ou vilarejo, ou com italianos de outras províncias que entendessem ou tivessem formas dialetais próximas ao vêneto, fosse o italiano. Pela referida linha de raciocínio, é interessante destacar que o termo talian, em trentino, tem o significado de italiano, como foi possível verificar por meio de consultas online, segundo as quais trata-se de um adjetivo e substantivo masculino com o significado de italiano ${ }^{4}$.

Ao buscarmos um dicionário friulano, encontramos o site friulano.net que, entre vários documentos sobre essa língua, oferece também um programa de suporte ao usuário, que ao ponderar sobre o grande dizionario bilingue italiano-friulano, apresenta o enunciado da seguinte forma: Grant dizionari bilengal talian-furlan.

Entretanto, chamou-nos a atenção o fato de encontrarmos, em semelhantes dicionários online, o acréscimo de outro sentido à palavra: em um $b \log ^{5}$, o termo talian no dialeto trentino significa italiano, mas, também, confere o significado de forasteiro, isto é, estrangeiro que não pertence à Itália.

Tal fato vem confirmar o que destaca Fumich (2007, p. 44), ao explicar que talian pode ter, de fato, dois sentidos no dialeto da cidade de Trieste, que pertence à região do Friuli Venezia Giulia. Trata-se de uma abordagem que remonta aos tempos antes da grande imigração e que talvez corrobore as razões do nome talian hoje no Brasil:

O que dizer do termo talian do dialeto triestino. Com certeza, talian corresponde a italiano, mas isso não é tão linear assim. Tomamos o dicionário de Pinguentini para não sermos tachados de oportunistas. O dicionário indica: sim, falo italiano diz-se a quem demora a compreender; falar italiano corresponde a falar o dialeto, enquanto a quem fala a língua, diz-se que fala o toscano. Bendito, meu Deus, sou triestina e falo só italiano. Para confundir ainda mais, se bem me lembro, com o termo talian, o povo citado por Pinguentini ${ }^{6}$ costumava, após o retorno da Itália a Trieste, principalmente os italianos do Sul. ${ }^{7}$

Compreendemos que, efetivamente, o uso de uma língua não tem fronteiras, não cabe em formas preestabelecidas; o sentido das palavras pode ser ampliado, modificado ou deslocado, conforme a necessidade dos que as veiculam. Assim, acreditamos na possibilidade de que os imigrantes da primeira onda de imigração para o Brasil, tanto sentindo-se italianos ou estrangeiros, usariam o adjetivo talian. Tal fato pode ser explicado levando em consideração que regiões como Veneto, Trentino Alto Adige e Friuli - Venezia Giulia - o trivêneto, que pertenciam, no período imigratório, ao Império Austríaco, não eram italianos, mas estrangeiros na Península Itálica.

\footnotetext{
3 "El nome Talian el vien dei noni, che sempre i disea: Noantri semo Taliani, par questo parlemo in Talian". 4 Dicionário trentino de Aldo Aneggi. Disponível em: <http://www.diaolin.com/wordpress/?page_id=149>e $<$ http://pulcinella291.forumfree.it/?t=54341097>. Acesso em: 15 mar. 2019.

5 Disponível em: <http://lagorai.blogspot.com.br/>. Acesso em: 15 mar. 2019.

$6 \quad$ Fumich cita Pinguentini, o autor do dicionário publicado em 1986.

$7 \quad$ "Che dire poi del termine 'talian' del dialetto triestino. 'Talian' vale dire 'italiano', certamente, ma la cosa non è così lineare. Prendiamo il Pinguentini per non essere tacciati di strumentalizzare. Il vocabolario alla voce aggiunge: 'è sì che parlo talian, si dice a chi tarda a capire'; parlar talian vale parlare il dialetto, mentre chi parla in lingua, il popolo dice che parla 'toscàn'. Benedetto, mi son triestina e parlo solo talian. E in aggiunta, per confondere ulteriormente se non ricordo male, col termine 'talian' il popolo citato da Pinguentini usava, dopo il ritorno dell'Italia a Trieste, apostrofare soprattutto i meridionali [...]”.
} 


\section{O talian não é uma língua homogênea}

Acreditamos que, se as heterogeneidades de falares e de culturas foram trazidas ao Brasil, seria bem arriscado fazer uma afirmação sobre homogeneidade cultural e linguística em solo brasileiro. Assim como em uma língua dita unificada ocorre variação e mudança, o mesmo se dá com os falares dialetais; ou seja, quanto maior o contato, maior a influência nos vários níveis da língua, seja lexical, fonológico, sintático e outros.

Para Certeau (1982, p. 222), haverá sempre outras vozes rompendo a unicidade desejada:

Não existe voz pura, porque ela é sempre determinada por um sistema (familial, social, etc) e codificada por uma recepção. Mesmo que as vozes de cada grupo componham uma paisagem sonora - um sítio sonoro - facilmente reconhecível, um dialeto - um sotaque - se destaca por seu traçado numa língua, como um perfume; mesmo que uma voz particular se distinga entre mil por acariciar ou irritar o corpo que ouve, instrumento de música tocado por essa mão invisível, não há tampouco unicidade entre os ruídos da presença, cujo ato enunciador influencia uma língua quando a fala.

Embora haja concordância em relação ao modo como foi se constituindo o talian, ainda ressoa, nos discursos, o imaginário da língua homogênea. O talian, com toda gama de variação e mudanças que foram acontecendo e continuam a ocorrer, não tem nada de homogêneo. Aliás, essa língua comum continua mudando. Na concepção do mencionado autor, aliás, o plural é algo originário e legítimo.

Honorio $\operatorname{Tonial}^{8}(2008, \mathrm{~s} / \mathrm{n})$ ressalta que o talian é uma língua em movimento como qualquer outra língua falada. Segundo ele, a língua está em crescente atualização, incorporando neologismos e formas idiomáticas que resultam do surgimento de novas denominações e interações.

Calvet (2002, p. 41) enfatiza que, se grupos com línguas diferentes, estando em contato, têm necessidades de se comunicar, eles vão inventar para si outra forma de língua aproximativa, geralmente uma língua mista. Luzzatto (1993, p. 30), então, destaca que o idioma talian não surgiu de uma hora para outra, mas houve um processo, que aconteceu lentamente, à medida que os trentinos, friulanos, lombardos e vênetos iam estreitando contatos, fora do contexto geográfico italiano.

Entendemos que não é possível admitir, exatamente como e em quais condições se processam as influências e mudanças de ordem linguística e é uma tarefa difícil indicar, com exatidão, qual influência iniciou-se primeiro. A esse respeito, concordamos com Confortin (1998, p. 35), quando pondera que

Todas as mudanças processaram-se de forma lenta e foram introduzidas variações mínimas de modo a não provocar alterações consideráveis na língua. As novas introduções, aceitas e assimiladas por toda comunidade linguística, não afetaram a natureza social da linguagem; em cada ato comunicativo só foram introduzidas variações mínimas - porém, contínuas - para que o sistema recebido pudesse continuar a ser entendido.

Para a autora, em sua pesquisa, as interferências lexicais são frequentes e “[...] são muitos 
os vocábulos da língua portuguesa usados na comunicação em dialeto italiano ou vocábulos de dialetos empregados em comunicações realizadas em português" (CONFORTIN, 1998, p. 36). Assim, seguem alguns exemplos da pesquisa em pauta: "tea rossa se piantea de tuto" (nessa frase, a palavra rossa ${ }^{10}$ tem o significado de roça, sendo usada como sinônimo de colônia); ocorrem, também, empréstimos do português: "careta para carroça ou carreta; tacoara por taquara; capoeron por capoeirão". Segundo a descrição de Confortin, tais palavras são do português, mas receberam o acento (sotaque) italiano. Para a autora (op. cit.), quando acontecem empréstimos lexicais, ocorrem, também, empréstimos fonológicos. Os exemplos mostram alguns dos fenômenos que se realizam, mas não iremos aprofundar aqui sua descrição, pois não é esse o objetivo deste artigo.

De início, os empréstimos da língua portuguesa se davam nas interações em que lhes faltavam palavras para nominar objetos, animais e situações desconhecidas. Confortin (1998, p. 29) salienta que os termos empregados estavam relacionados "[...] a novos tipos de acidentes geográficos, fauna, flora, terminologias referentes a animais, a medidas, pesos, contatos com o comércio, termos referentes a usos e costumes, etc.". E a autora, no decorrer de seu trabalho, vai especificando itens dos quais citamos aqui a título de exemplo: a capoeira para designar um mato fino; o arado para trabalhar com os bois, canga dos bois, galpão/galpon (com acento italiano); o paiol, que era o local onde se guardava a colheita; mangual, enquanto instrumento utilizado para debulhar cereais; bolasse (com acento italiano) para bolachas caseiras; e os termos para designar as madeiras - grapia, gabriúva, cerno, angico, entre outros.

Houve, ainda, empréstimos da língua portuguesa que foram talianizados na oralidade; a pesquisa de Confortin (1998) evidencia as seguintes palavras: (sinele para chinelos, caciassa para cachaça, simarón ou scimarón para chimarrão, Cassia para Caxia, entre outros exemplos). Em nossa pesquisa, observamos que haveria duas possibilidades de empréstimo para as palavras caciassa e chimarrom. Como já mencionado, acenamos para a possibilidade da ocorrência do empréstimo a partir da influência da língua espanhola de fronteira (Uruguai e Argentina); assim, ouvindo ca(tchi)aça do espanhol, o imigrado poderia ter entendido caciassa, já que, no talian, a letra c, seguida das vogais e e i, compõe os sons tche e tchi, caso de empréstimo por adaptação (WEINREICH, 2008). No caso das palavas sinele, simarrom e bolasse, nossa hipótese é que tenha ocorrido o processo de adaptação dos fonemas ch ou $\mathbf{x}$ para o $\mathbf{s}$ ou $\mathbf{s}$ duplo da língua materna ${ }^{11}$ : chinelas/sinele, chimarrom/simarrom, bolachas/bolasse e Caxias/Cassia .

Há empréstimos que permaneceram com a forma do português, como bola, bolo, capoeira, banco (móvel e também estabelecimento bancário), bandido, banana, rapadura etc. Existem, ainda, outros exemplos de vocábulos emprestados do português que anulam a nasalização, realizando uma monotongação, como dedicassion (dedicação), salvassion (salvação), pon (pão) (LUZZATTO, 2000). Há de se considerar, também, que há semelhanças no português e no dialeto vêneto entre as palavras elencadas. Outro ponto que deve ser ressaltado é que isso acontece com qualquer italiano - de qualquer região - pois não existe a nasal na língua italiana.

$9 \quad$ Na roça/colônia se plantava de tudo.

10 Rossa também pode significar 'vermelha' tanto no dialeto vêneto quanto no Italiano padrão (LUZZATTO, 2000, p. 293).

11 A base do talian está na língua vêneta; logo, teríamos algumas possíveis situações de substituições dos sons. De acordo com Belloni (2009, p. 40), na gramática do vêneto, o x é usado com o som de s sonora. Daí a probabilidade dos descendentes terem ouvido o som ( $x$ ou $\boldsymbol{c h}$ ) em bolachas e ajustado para a língua materna como bolasse; chinelas- sinele e Caxias- Cassia. 
Ao consultarmos o dicionário vêneto Nuovo dizionario da scarsèa Veneto Italiano (BASSO, 2012, p. 256), foi possível verificar que a palavra 'salvação' tem como correspondentes salvessa, em vêneto, e salvezza ou salvazione, em italiano. Embora o dicionário Treccani ${ }^{12}$ aponte para uma linha tênue de diferença entre as duas palavras: salvezza está mais relacionado a ser salvo de algum perigo, uma doença ou situação difícil; enquanto salvazione tem o sentido relacionado ao âmbito religioso. De qualquer forma, não conseguimos maiores informações sobre o uso dessas palavras no contexto dos imigrantes, além de não ser nosso objetivo neste estudo.

Ao que parece, o processo de assimilação tornou-se mais fácil para os imigrantes e descendentes, já que, no português, temos 'salvação' e, no talian, transformou-se em salvassion. Em relação ao empréstimo linguístico, Confortin (1998) também mostra, em seus estudos, “[...] a realização da vogal posterior média, fechada, nasal /o/ pelo ditongo nasal /ão/: galpon - galpão; facon-facão; baracon - barracão".

É natural que interferências e empréstimos ocorram em relação à língua do país que os recebe. Portanto, é válido apontar que existem concepções de interferências/influências linguísticas, amparando-se somente no indivíduo e que são baseadas na ideia de desvio da norma de uma das línguas em contato. Para vertentes linguísticas mais rígidas, uma língua, para ser aceita, necessita estar enquadrada em uma norma de padronização. Ademais, não pode ser bilíngue o sujeito que veicula uma língua de maneira imperfeita. Tais "interferências" verbalizadas gerariam estruturas linguísticas agramaticais (WEINREICH, 2008).

Na concepção de Rossi-Landi (1985, p. 74), com a qual concordamos, o homem produz e faz uso da palavra de acordo com a sua necessidade - a comunicação. Segundo o autor, "[...] falando, eles exprimem a si próprios e se mantêm em contato comunicativo. O uso da linguagem apresenta-se como natural".

\section{Situação atual do talian: o reconhecimento como língua}

O talian foi a primeira língua de imigração, no Brasil, a solicitar, em 2001, o seu reconhecimento. Com isso, seus representantes do Rio Grande do Sul - o Instituto Vêneto e a Universidade de Caxias do Sul - somaram forças e encaminharam o pedido ao IPHAN, realizando com essa iniciativa o passo principal para dar maior visibilidade à língua.

A formulação do inventário contou com a participação dos professores Marley Terezinha Pertile, Alcione Moraes Jacques Maschio, Luciana Santos Pinheiro e Cléo Vilson Altenhofen, bem como de alunos bolsistas da Universidade de Caxias do Sul e da Universidade Federal do

12

salvézza.f. [der. Di salvo]. - 1. L'essere salvo; il salvarsi, l'essere salvato: s. dai pericoli, dai nemici, dalle malattie;cercare, ottenere, trovare la s.; ogni speranza di s. era perduta; non c'è via di s.; pensare, provvedere alla propria s.; deve a lui la sua s.; lottare per la s. della patria. Per metonimia, la persona, la cosa, il mezzo che salva, che ha salvato: sei stato tu la mia s.; questa testimonianza sarà la s. dell'imputato; il fido ottenuto dalla banca fu la sua salvezza. Per l'espressione fig. àncora di s., v. àncora, $n .1$ a. 2. Salvazione, nel senso religioso: la dottrina della s. nel cristianesimo; pregare per la s. dell'anima, per la s. eterna; senza fede non c'è salvezza. Per l'Esercito della s., v. esercito, n. 2 b. 3. Nel calcio e in altri sport di squadra regolati da campionati con classifica a punti, i risultati utili con cui nella fase finale del girone di ritorno si riesce a evitare la retrocessione nella serie o divisione inferiore: lottare per la s.; domenica si giocherà per la salvezza (Disponível em: <http://www.treccani.it/vocabolario/salvezza>. Acesso em: 30 jun. 2019). salvazióne s. f. [dal lat. tardo salvatio -onis, der. di salvare «salvare»], letter. - Il salvare, il salvarsi, quasi esclusivam. con riferimento alla salvezza dell'anima: Andovvi poi lo Vas d'elezione, Per recarne conforto a quella fede Ch'è principio alla via di s. (Dante); la grazia che chiedo per me al Signore, la sola grazia, dopo la salvazion dell'anima, è che mi faccia tornar con voi (Manzoni); pregare per la propria s., per la s. eterna; luogo di s., il purgatorio, il paradiso (Disponível em: <http://www.treccani.it/vocabolario/salvezza>. Acesso em: 30 jun. 2019). 
Rio Grande do Sul.

O projeto para o inventário de língua de imigração foi realizado na Universidade de Caxias do Sul, na qual há um núcleo de pesquisa, intitulado Elementos Culturais da Imigração italiana no nordeste do Rio Grande do Sul. O programa, criado em 1978, dedica-se ao levantamento sistemático de bens e valores das comunidades rurais da região, no intuito de resgatar, preservar e valorizar a cultura do imigrante italiano.

O inventário do talian, segundo seus idealizadores, teve como finalidade registrar de forma fidedigna, objetiva e sistemática a realidade e o contexto de uso. De acordo com o documento, publicado em 2010, "o conhecimento dessa realidade, quer dizer, seu diagnóstico, contribui para visualizar possibilidades futuras de promoção e revitalização da língua" (p. 1).

O Projeto Piloto de Inventário seguiu as determinações do IPHAN, que tinha como objetivo desenvolver e testar uma metodologia de trabalho que respeitasse as especificidades de uma língua de imigração.

O documento, então, agregou informações sobre descendentes, língua e cultura de vários estados brasileiros que têm suas origens atreladas ao italiano do Norte da Itália, vindo da primeira leva de imigração. Nesse caso, não somente aqueles que estão nas antigas, novas e novíssimas colônias do RCI, no Rio Grande do Sul ou Santa Catarina, mas, também, incluiu os seus desdobramentos no Oeste de Santa Catarina, Oeste do Paraná, mais uma parte do estado do Mato Grosso e o estado do Espírito Santo.

A imigração italiana no estado do Espírito Santo também foi significativa e grande parte dos imigrantes também eram de origem vêneta. Entretanto, por não conhecermos muito bem a realidade da forma de estabelecimento no local, da sistematização e dos contatos linguísticos, temos algumas ressalvas quanto à afirmação de ser o talian a língua veiculada nas colônias que se formaram naquela região.

Em 2010, o então presidente da República, Luiz Inácio Lula da Silva, assinou o Decreto 7387, em que institui o Inventário Nacional da Diversidade Linguística (INDL). Entre as línguas a serem inventariadas está o talian. Segundo o site do IPHAN, “[...] o inventário é um meio de identificação, documentação, reconhecimento e valorização das línguas portadoras de referência à identidade, à ação, à memória dos diferentes grupos formadores da sociedade brasileira". Sendo assim, é importante que haja pesquisas sobre o tema, a fim de divulgar essa língua tão rica cultural quanto linguisticamente. Instituições como a Universidade de Caxias do Sul (UCS) e a Universidade Federal do Rio Grande do Sul (UFRG) empenham-se em pesquisar o citado idioma e seus falantes, como mostram as pesquisas de Frosi (1998), Maestri (2000), Costa (2000), Luzzatto (1993, 1998), dentre outros.

Em 18 de novembro de 2014, no Seminário Ibero Americano da Diversidade Linguística, realizado no município de Foz do Iguaçu, deu-se o reconhecimento do talian como língua pertencente ao patrimônio imaterial e cultural do Brasil. A partir desse momento, fica claro que os dialetos dos imigrantes italianos que deram origem ao talian são das seguintes regiões: Vêneto (54\%), Lombardia (33\%), Trentino-Alto Adige (7\%), Friuli-Venezia Giulia (4,5\%) e 
Piemonte, Emilia-Romagna, Toscana e Ligúria (001,5 \%) (FROSI \& MIORANZA, 1975, p. 36). Entendemos, portanto, que o talian não é a língua italiana oficial, nem é qualquer um dos seus dialetos formadores, tampouco o vêneto, mesmo sendo este seu principal elemento formador. O talian é língua formada nas Serras Gaúchas, hoje presente em muitas regiões brasileiras por força das migrações internas, com destaque nos estados do Sul do Brasil: Rio Grande do Sul, Santa Catarina e Paraná. Cabe dizer, no entanto, que os estados catarinense e paranaense também receberam imigração direta, o que gerou a mescla de dialetos com o português local.

Em relação à divulgação, a internet tem-se configurado como forte aliada para a difusão e manutenção do talian. Nos dias de hoje, a língua atravessa um período de grande produtividade, que se caracteriza pelo surgimento de publicações impressas e virtuais enfocando a sua história e a de seus falantes, facilitando a produção e a manutenção dos artigos e das matérias sobre o talian. A maioria do material é divulgado de modo virtual: os blogs, por exemplo, têm contribuído, de forma significativa, no trabalho de transmissão de informações, imagens e vídeos. Podemos citar o blog do Talianeto ${ }^{13}$, que tem como escritor Honório Tonial, que, a seu turno, entre vários artigos políticos, escreve histórias sobre e em talian.

O site Oriundi $^{14}$ pode ser visualizado em língua italiana padrão e em português, contudo, com frequência, publica notícias sobre o talian. Outro site interessante que contém artigos sobre a importância de se preservar a cultura e a língua pertence ao escritor Silvio Santin ${ }^{15}$, que possui muitas publicações visando à difusão e manutenção da língua. Já o Talian Brasil ${ }^{16}$ é uma revista online com publicações de autores como Darcy Loss Luzzatto, Honório Tonial, Rovílio Costa e Giuseppin Oro. Além disso, no próprio site, pode ser ouvido um programa de rádio em talian e acompanhado o cronograma de eventos relacionados à cultura taliana: como os corais, grupos de danças, bem como as datas e os locais onde se apresentarão.

A editora Este foi fundada pelo frei, professor e escritor Rovílio Costa, em 1974. Suas publicações têm como base obras que versam sobre a história da imigração no contexto sul rio-grandense. Entretanto, os títulos não se referem apenas à imigração italiana, mas ao "[...] resgate das origens, genealogias, culturas e dialetos, relacionados às imigrações judaica, polonesa, italiana, alemã, açoriana, portuguesa, africana, etc. e as populações indígenas do solo gaúcho". ${ }^{17}$

O site Caminho de Pedras ${ }^{18}$ apresenta dados históricos, fotos e informações turísticas para agendamento de visitas. O local foi declarado patrimônio histórico do estado do Rio Grande do Sul; sua área abrange "[...] as linhas Palmeiro e Pedro Salgado, localizadas nos municípios de Bento Gonçalves e Farroupilha, até o limite do município de Caxias do Sul, passando por Caravaggio". É considerado, também, um museu vivo, pois conserva e dinamiza a cultura que os imigrantes italianos trouxeram à Serra Gaúcha a partir de 1875.

\footnotetext{
13 Disponível em: <http://htonial.blogspot.com.br/>. Acesso em: 11 abr. 2019.

14 Disponível em: <http://www.oriundi.net/site/oriundi.php?menu=noticiasdet\&id=21857>. Acesso em: 11 abr. 2019.

15 Disponível em: <https://silvinosantin.wordpress.com/category/textos-em-talian/>. Acesso em: 11 abr. 2019.

16 Disponível em: <http://www.talianbrasil.com.br/>. Acesso em: 11 abr. 2019.

17 Disponível em: <http://www.esteditora.com.br/index.php?route=information/information\&information id>. Acesso em: 11 abr. 2019.

18 Disponível em: <http://www.caminhosdepedra.org.br/pt/>. Acesso em: 11 abr. 2019.
} 
O roteiro turístico foi idealizado pelo engenheiro Tarcísio Vasco Michelon e pelo arquiteto Júlio Pozenato. As visitas turísticas fizeram surgir " [...] várias iniciativas que visam a preservar não só o patrimônio material, mas também o imaterial [...]”, como, por exemplo, a preservação da língua dos imigrantes - o talian, a Casa da Memória e os grupos artístico-culturais, que se apresentam em ocasiões especiais.

Destaca-se, ainda, o documentário Brasil Talian, produzido pelo Círculo Cultural ÍtaloBrasileiro de Antônio Prado ${ }^{19}$, desenvolvido pelo historiador Fernando Roveda e financiado pela Lei de Incentivo à Cultura Federal - Mecenato do Ministério da Cultura do Brasil. O filme foi rodado entre os anos de 2011 e 2014 e contém reflexões acerca do talian, por meio de depoimentos que foram gravados nas colônias da Serra Gaúcha - Flores da Cunha, Nova Pádua e Antônio Prado; e do Espírito Santo - Venda Nova do Imigrante e Santa Tereza; além das cidades italianas Venezia, Trento, Genova e Vicenza.

De grande alcance, evidenciam-se as várias emissoras de rádio que veiculam programas semanais em língua taliana. Citamos algumas: Talian - nostra lengua, Nostro talian, Viva el talian, Talian Brasil, Taliani bona gente, Talian - Antonio Prado, Cantando in talian, Ricordi dei noni, Ricordi di Italia, Italia del mio cuore, entre outras.

Um radialista e humorista bastante famoso entre os descendentes é Edgar Maróstica, do município de Serafina Corrêa, no Rio Grande do Sul, que faz parte do programa taliani nel mondo (http://www.talianinelmondo.com.br), transmitido em mais de 40 Rádios do Brasil. Também há programação semanal em cidades do Rio Grande do Sul: em Guaporé (www.radioliberalfm.com.br); Veramente talian, em Veranópolis (www.radio961fm.com); e La voce del veneto, em Serafina Corrêa, (www.odisseia.fm.br), juntamente com Paulo Massolini, outro grande difusor do talian.

Há grandes figuras humorísticas no contexto gaúcho que, com o boom da internet e das redes sociais, vieram a publicizar, com mais abrangência, seus trabalhos. Entre essas, citamos o Radicci, interpretado pelo jornalista, cartunista e humorista Carlos Henrique Iotti, de Caxias do Sul. Iotti possui vários livros publicados, em especial um que leva seu próprio nome, Radicci, de 1983. Seu personagem mais famoso, o qual representa um ítalo brasileiro, também conhecido como gringo ${ }^{20}$, “[...] de temperamento forte, amante do vinho e do ócio. É casado com Genoveva e pai de Guilhermino. O personagem representa a típica família de descendentes italianos". O Radicci faz sempre piadas e brincadeiras, enfatizando a interferência/influência da pronúncia do italiano, segundo ele o 'sotacón' (DELLA BELLA, 2002).

Apesar de Tchó e Beppi ${ }^{21}$ serem bastante conhecidos na região Sul brasileira, os artistas são do estado do Mato Grosso, de Sinop, cidade que tem o maior número de seguidores. Em seguida, estão as cidades gaúchas de Porto Alegre e Caxias do Sul. Em Santa Catarina, Chapecó é a quarta em audiência e, em quinto lugar, aparece a cidade de São Paulo. Embora as apresentações sejam humorísticas, os conteúdos versam sobre assuntos atuais, principalmente do cenário político. Os personagens não falam em talian, mas brincam, utilizando palavras como

19 Disponível em: <http://www.cnec-antonioprado.com.br/news/documentario-brasil-talian>.

Acesso em: 12 abr. 2019.

$20 \quad$ Disponível em: < $\quad$ www.revistasamizdat.com/2008/11/entrevista-carlos-henrique-iotti. html\#sthash.6M1ZYqMD.dpuf; http://iotti-radicci.blogspot.com.br/>. Acesso em: 12 abr. 2019.

21 Disponível em: <http://www.tbitalianos.com.br/Noticias/56/>. Acesso em: 24 jun. 2019. 
Dio Sacramento, quela cosa, Porca Miseria ${ }^{22}$, demo via e ressaltam o sotaque tipicamente italiano como non, enton, entre outros.

Tem-se destacado, na internet, no canal youtube, vídeos que retratam "as coisas que se falam na Serra". As histórias são interpretadas por um casal de ítalo-gaúchos que demonstram situações peculiares com palavras, frases e expressões próprias de descendentes de italianos. Nos episódios, são evidentes frases como: "não esquece a japona, neno!" (forma de referir-se à criança), Madonna e Porco Dio. São recorrentes também: "Vecia, bota os pinhon pra cozinha!", "Sacramento, pára de ciacolar!", "Pára de fazer ciuca, porco can!", entre tantas outras. Ademais, a comida é assunto bastante presente nas falas: pinhon, pon, grostoli, agnolini, bucho, salame, vinho, milho etc. ${ }^{23}$.

Citamos, além disso, o site de relacionamentos Facebook, que propicia a divulgação e as interações, por meio de páginas pessoais, comunidades e grupos, a saber: Parla Talian, Taliani Bona Gente, Giusepin Oro, Revista Talian Brasil, Talian Nostra lengua, Cantando in Talian, Descendentes de (i)talianos de Cascavel - Paraná e tantos mais.

\section{Considerações finais}

Finalizamos nossa reflexão concordando com o argumento dos autores Luzzatto e Costa, segundo os quais o talian tem suas raízes nos dialetos do Trivêneto e da Lombardia, mas é língua genuinamente brasileira, pois sua constituição e a sua história se dá em terras Sul-brasileiras. Entretanto, sendo uma língua viva está sujeita a transformações como qualquer outra, portanto, não pode ser considerada homogênea.

Ressaltamos que essa língua percorreu um árduo e longo caminho e, a partir dessa luta pelo/ do talian, produziram-se muitos frutos, como por exemplo, os grupos de filó, grupos de danças folclóricas, publicações de livros e artigos. Destacamos ainda o poder que exercem os meios de comunicação atual, os quais têm abrangência e rapidez incomparáveis, por isso, fundamentais para o alcance da população que, atualmente, está cada vez mais "cibernética". Quem busca informações a respeito dessa língua/cultura pode se inteirar mais sobre hábitos, costumes e eventos culturais. Distinguimos, também, que, através desses meios de comunicação, mesmo com perdas e mudanças linguísticas, "as línguas propõem-nos um modelo de imortalidade" (HAGĖGE, 2000, p. 19), e consideramos, assim, fundamental que se aprofundem as pesquisas sobre o talian, a fim de que sejam definidos os limites - se é que é possível - dessa língua nascida no Sul do Brasil e de suas possíveis variedades.

\footnotetext{
22 Palavras do Italiano padrão.

23 Disponível em:

<http://zh.clicrbs.com.br/rs/vida-e-estilo/verao/noticia/2013/02/sucesso-na-internet-serie-coisas-que-a-serra-fala-chega-ao-litoral-com-expressoes-tipicas-4042870.html>. Acesso em: 24 jun. 2019. Disponível em:

<http://pioneiro.clicrbs.com.br/rs/culturaetendencias/almanaque/noticia/2014/05/farroupilhenses-lancam-coisas-que-a-serra-fala-na-copa-4495039.html>. Acesso em: 24 jun. 2019.
} 


\section{Referências}

BASSO, V. di. Nuovo dizionario da scarsèa: Veneto Italiano. Scantabauchi: Editoriale Programma, 2012.

CALVET, L. J. Sociolinguística: uma introdução crítica. São Paulo: Parábola Editorial, 2002.

CARBONI, F. \& MAESTRI, M. Raízes italianas do Rio Grande do Sul: 1875-1997. Passo Fundo: UPF, 2000.

CERTEAU, M. de. A escrita da história. Rio de Janeiro: Forense Universitária, 1982.

CONFORTIN, H. A faina linguística. Porto Alegre: EST/UCS, 1998.

COSTA, R.; BONI, L. A. de. Nós, os gringos. In: MAESTRI, Mário (org.). Nós, os ítalo-gaúchos. 2. ed. Porto Alegre: Ed. da Universidade, 1998.

Histórico de São Leopoldo, 2000.

. Dissionàrio: la grande stòria. Porto Alegre: Academia Rio-Grandense de Letras Instituto

DELLA BELLA, M.A. Resenha. IOTTI, Carlos Henrique. Zona rural. Porto Alegre: L\&PM, 2002. Revista de Italianística XII, 2006, p.

FROSI, M. V. A linguagem oral da região de colonização italiana no sul do Brasil. In: MAESTRI, M. (Org.). Nós, os Ítalo-gaúchos. Porto Alegre: Universidade/UFRGS, 1998.

; RASO, T. O italiano no Brasil: um caso de contato linguístico e cultural. In: MELLO,

H., ALTENHOFEN, C. V. e RASO, T. Os contatos linguísticos no Brasil. Belo Horizonte: Editora UFMG, 2011.

1975. . Imigração italiana no nordeste do Rio Grande do Sul. Porto Alegre: Editora Movimento, 2007.

FUMICH, S. Il pozzo e le parole: tre scritte sulla questione delle foibe. Brembio: Ca' La Gatera,

LUZZATTO, D. L. Gramática, História e Cultura. 1998. El nostro parlar. Porto Alegre: Sagra Luzzatto, 1993.

. Dicionário talian-português. Porto Alegre: Sagra Luzzatto, 2000.

MAESTRI, M. Os senhores da serra: a colonização no Rio Grande do Sul. Passo Fundo: UPF, 2000.

MAGGIO, G. Esempi di esitazione nella riformulazione del discorso interlinguistico degli immigrati pedrinhenses. Revista de Italianística IX, 2004.

LEOPOLDINO, E. A. O dialeto trentino da Côlonia Tirolesa de Piracicaba: aspectos fonéticos e lexicais. Tese (Doutorado) - Universidade de São Paulo: São Paulo, 2014.

PINGUENTINI, Gianni. Nuovo dizionario del dialetto triestino: storico, etimologico, fraseologico. Bologna: Del Bianco, 1986.

RIBEIRO, A. R. R. Descendentes de (i)talianos de Cascavel/PR: língua e cultura encobertas. 2016. Tese (Doutorado). Faculdade de Filosofia, Letras e Ciências Humanas. Universidade de São Paulo: São Paulo, 2016.

ROSSI-LANDI, F. A linguagem como trabalho e como mercado. Trad. A. F. Bernardini. São Paulo: Difel, 1985.

WEINREICH, U. Lingue in Contatto. Novara: De Agostini Scuola, 2008.

Recebido em: 12/10/2019

Aprovado em: 05/12/2019 